\title{
Short communication: Reproduction outcomes in dairy heifers following a 14-d progesterone insert presynchronization protocol
}

\author{
C. K. Claypool, ${ }^{1}$ J. A. Spencer, ${ }^{1}$ S. Menegatti Zoca, ${ }^{1}$ B. Shafii, ${ }^{2}$ W. J. Price, ${ }^{2}$ A. Ahmadzadeh, ${ }^{1}$ N. R. Rimbey, ${ }^{3}$ \\ and J. C. Dalton ${ }^{4 *}$ \\ ${ }^{1}$ Animal and Veterinary Science Department, University of Idaho, Moscow 83844 \\ ${ }^{2}$ Statistical Programs, College of Agricultural and Life Sciences, University of Idaho, Moscow 83844 \\ ${ }^{3}$ Agricultural Economics and Rural Sociology Department, University of Idaho, Moscow 83844 \\ ${ }^{4}$ Animal and Veterinary Science Department, University of Idaho, Caldwell 83605
}

\section{ABSTRACT}

The objectives were to evaluate pregnancy per artificial insemination $(\mathrm{AI})$, days to first $\mathrm{AI}$, and proportion pregnant within $7 \mathrm{~d}$ of AI eligibility in dairy heifers subjected to presynchronization compared with dairy heifers not presynchronized. Thirty days before AI eligibility, Holstein heifers were assigned randomly to 1 of 3 groups: 14-d controlled internal drug release (CIDR; containing progesterone) presynchronization, $\mathrm{PGF}_{2 \alpha}$ presynchronization, or control (no presynchronization). Heifers in the 14-d CIDR presynchronization treatment $(\mathrm{n}=119)$ received a CIDR on $\mathrm{d}-30$, which was removed on $\mathrm{d}-16$, followed by an injection of $\mathrm{PGF}_{2 \alpha}$ upon entry to the breeding program (d 0 ). Heifers in the $\mathrm{PGF}_{2 \alpha}$ presynchronization treatment $(\mathrm{n}=118)$ received an injection of $\mathrm{PGF}_{2 \alpha}$ on $\mathrm{d}-11$ and $\mathrm{d} 0$. Control heifers $(\mathrm{n}=$ 121) were not presynchronized and received an injection of $\mathrm{PGF}_{2 \alpha}$ on $\mathrm{d} 0$. All heifers received tail paint on $\mathrm{d} 0$ to facilitate once-daily detection of estrus (based on paint removal). Heifers detected in estrus received AI with conventional semen on the same morning as detected estrus. Generalized linear mixed models were used to assess mean treatment differences. Following $\mathrm{PGF}_{2 \alpha}$ treatment on $\mathrm{d} 0$, more heifers were detected in estrus in the first $7 \mathrm{~d}$ after eligibility in the 14-d CIDR group (95.8\%) compared with the $\mathrm{PGF}_{2 \alpha}(74.6 \%)$ and control $(66.9 \%)$ groups. Days to first AI differed between treatments $\left(14-\mathrm{d}\right.$ CIDR $=3.6 \mathrm{~d}$ vs. $\mathrm{PGF}_{2 \alpha}=5.0 \mathrm{~d}$ vs. control $=6.8 \mathrm{~d}$ ). Pregnancy per AI for first AI within $7 \mathrm{~d}$ of eligibility was $71.9 \%$ (14-d CIDR), $58.0 \%\left(\mathrm{PGF}_{2 \alpha}\right)$, and $61.7 \%$ (control), and differed between 14-d CIDR and $\mathrm{PGF}_{2 \alpha}$ heifers. Presynchronization with a 14-d CIDR increased the proportion of heifers pregnant in the first $7 \mathrm{~d}$ of eligibility (14-d CIDR $=68.9 \%$ vs. $\mathrm{PGF}_{2 \alpha}=$

Received May 21, 2019.

Accepted July 17, 2019

*Corresponding author: jdalton@uidaho.edu
$43.2 \%$ vs. control $=41.3 \%$ ). Projected days on feed (d 0 to projected calving date) were 295 (14-d CIDR), $302\left(\mathrm{PGF}_{2 \alpha}\right)$, and 305 (control), and were different between the 14-d CIDR and control heifers. The potential economic benefit to the producer was $\$ 15.85$ per heifer presynchronized with a 14-d CIDR protocol compared with the control group. Treatment of dairy heifers with a 14-d CIDR effectively presynchronized estrus, resulting in a greater proportion detected in estrus, reduced days to first AI, and an increased proportion of heifers pregnant within the first $7 \mathrm{~d}$ after breeding eligibility compared with heifers presynchronized with a single $\mathrm{PGF}_{2 \alpha}$ injection and control heifers.

Key words: dairy heifer, pregnancy, presynchronization

\section{Short Communication}

Raising replacement heifers, together with the feed and labor costs associated with the lactating herd, is one of the largest expenses of a dairy farm (Frazer LLP, 2018). Feed is the major cost in raising replacement heifers, accounting for approximately 45 to $64 \%$ of total costs in Dutch and US dairy farms, respectively (Gabler et al., 2000; Mohd Nor et al., 2012). A delay in age at first pregnancy, from 13 to 15 mo, will lead to a delay in age at first calving, increased rearing costs, and lost income of $\$ 200$ per heifer (Lormore, 2006).

Reproductive programs for dairy heifers may include a single injection of $\mathrm{PGF}_{2 \alpha}$ to synchronize estrus, and facilitate estrus detection and AI (Lauderdale, 2009). Treatment of heifers not identified in estrus with a second dose of $\mathrm{PGF}_{2 \alpha} 11$ to $14 \mathrm{~d}$ after the first dose may cause heifers with an immature corpus luteum (CL) at the time of the first $\mathrm{PGF}_{2 \alpha}$ to regress the $\mathrm{CL}$ and exhibit estrus. Another method used to facilitate AI in dairy heifers includes the use of $\mathrm{GnRH}$, a controlled internal drug release insert (CIDR; $1.38 \mathrm{~g}$ of progesterone), and $\mathrm{PGF}_{2 \alpha}$ in a 5-d timed $\mathrm{AI}$ (TAI) protocol (Rabaglino et al., 2010; Lima et al., 2011, 2013; Silva et al., 2015). 
Presynchronization during the voluntary waiting period in lactating dairy cows is used to enhance pregnancy per AI (P/AI) to a TAI protocol (Moreira et al., 2001), or facilitate AI following detection of estrus, shortly after breeding eligibility (Chebel and Santos, 2010). In contrast, synchronization protocols for dairy heifers are typically initiated on the day of breeding eligibility (Stevenson et al., 2008) without presynchronization. Although a recent study (Karakaya-Bilen et al., 2019) reported a tendency for increased P/AI in heifers presynchronized with $\mathrm{PGF}_{2 \alpha} 2 \mathrm{~d}$ before initiating the 5-d TAI protocol, it remains unclear whether presynchronization is an effective strategy to increase reproductive performance and potentially reduce costs associated with raising dairy heifers.

A 14-d CIDR treatment has been shown to be effective to synchronize ovulation in beef and dairy heifers (Leitman et al., 2009; Escalante et al., 2013a). Long-term exogenous progesterone treatment, such as a CIDR insert for $14 \mathrm{~d}$, will inhibit estrus and ovulation, and induce a persistent dominant follicle capable of ovulation after CIDR removal (Ahmad et al., 1995; Roche et al., 1999; Escalante et al., 2013b). Ovulation of the dominant follicle results in synchronized estrus that can be used for presynchronization (Escalante et al., 2013b). Consequently, a $\mathrm{PGF}_{2 \alpha}$ injection administered $16 \mathrm{~d}$ after CIDR removal followed by AI upon detected estrus (Leitman et al., 2009) or an injection of GnRH and TAI $66 \mathrm{~h}$ after $\mathrm{PGF}_{2 \alpha}$ (Mallory et al., 2013) has resulted in acceptable fertility in beef and dairy heifers (58 and 70\% P/AI, respectively). Nevertheless, there is no information on the reproductive performance of dairy heifers presynchronized with a 14-d CIDR protocol during the immediate pre-breeding period.

Presynchronization is administered in the immediate pre-breeding period to maximize the expected benefits shortly after breeding eligibility. Therefore, our objectives were to evaluate $\mathrm{P} / \mathrm{AI}$, days to first $\mathrm{AI}$, and proportion pregnant within $7 \mathrm{~d}$ of eligibility in heifers subjected to presynchronization (14-d CIDR or $\mathrm{PGF}_{2 \alpha}$ ) compared with heifers not presynchronized. The hypotheses were that presynchronization of dairy heifers would result in similar P/AI but reduced days to first $\mathrm{AI}$ and an increased proportion pregnant within $7 \mathrm{~d}$ of eligibility compared with heifers not presynchronized.

The University of Idaho Institutional Animal Care and Use Committee approved all procedures used in this study. Holstein heifers $(\mathrm{n}=358)$ at a commercial heifer-raising facility in southwestern Idaho were used in this study. Heifers were housed in dry lots with selflocking stanchions. Heifers were fed a TMR twice daily that met or exceeded the nutritional requirements of Holstein heifers weighing $390 \mathrm{~kg}$ and gaining $0.9 \mathrm{~kg} / \mathrm{d}$ (NRC, 2001). The diet contained corn silage, alfalfa hay, mint silage, straw, liquid whey, dried distillers grains, and a mineral and vitamin supplement.

Following selection based on projected criteria on day of breeding eligibility $(\mathrm{BW} \geq 390.1 \mathrm{~kg}$, height at the withers $\geq 129.54 \mathrm{~cm}$, and age $\geq 12.5 \mathrm{mo}$ ), heifers were randomly assigned to treatments. Heifers in the 14-d CIDR presynchronization treatment $(\mathrm{n}=119)$ received a CIDR insert (Eazi-Breed CIDR; $1.38 \mathrm{~g}$ of progesterone; Zoetis, Florham Park, NJ) on d -30 for 14 d (Figure 1 ). On $\mathrm{d}-16$, immediately after CIDR removal, all heifers in the 14-d CIDR presynchronization treatment received an Estrotect patch (Rockway Inc., Spring Valley, WI) and were restrained in headlocks once daily for $7 \mathrm{~d}$ to facilitate detection of estrus. No heifers received $\mathrm{AI}$ at this time. On d 0 (16 d after CIDR removal), heifers received a single injection of $\mathrm{PGF}_{2 \alpha}(25 \mathrm{mg}$ i.m. of dinoprost tromethamine; Lutalyse, Zoetis). Heifers in the $\mathrm{PGF}_{2 \alpha}$ presynchronization treatment $(\mathrm{n}=118)$ received an injection of $\mathrm{PGF}_{2 \alpha}$ on $\mathrm{d}-11$ and on $\mathrm{d} 0$ (Figure 1$)$. Control heifers $(\mathrm{n}=121)$ were administered a single injection of $\mathrm{PGF}_{2 \alpha}$ on $\mathrm{d} 0$ in accordance with the current management strategy at the heifer-raising facility (Figure 1). Beginning on d 0, heifers received tail paint (Rust-oleum Specialty Fluorescent Orange, Vernon Hills, IL) and were restrained in self-locking stanchions each morning to facilitate once daily detection of estrus (based on paint removal) and AI. Heifers detected in estrus received AI on the same morning as detected estrus. Conventional semen from 6 sires and multiple suppliers was used for AI. All semen straws were thawed in a $35^{\circ} \mathrm{C}$ water bath for a minimum of $45 \mathrm{~s}$. Semen straws were provided thermal and hygienic protection at all times. A single inseminator with $>40$ yr of experience detected estrus and performed all inseminations. Pregnancy status was determined by the herd veterinarian via transrectal palpation of uterine contents 35 to $42 \mathrm{~d}$ after AI. Upon open diagnosis, heifers with a CL were administered $\mathrm{PGF}_{2 \alpha}$. Open heifers without a CL were rechecked each week (if not reinseminated) and administered $\mathrm{PGF}_{2 \alpha}$ when a CL was present. The breeding eligibility period, as determined by the heifer-raising facility management, was $120 \mathrm{~d}$.

Blood samples were collected from a subset of heifers (14-d CIDR, $\mathrm{n}=30 ; \mathrm{PGF}_{2 \alpha}, \mathrm{n}=29$ ) via coccygeal venipuncture into EDTA $\left(\mathrm{K}_{3}\right)$ blood collection tubes (Monoject; Kendall Tyco Healthcare, Mansfield, MA) (Figure 1). Personnel availability precluded the acquisition of blood samples from a subset of heifers in all 3 groups. Samples were collected on d $-30,-16,-11,0$, and on the day of AI for determination of progesterone concentration. Blood was collected before CIDR insertion on $\mathrm{d}-30$ and $1.5 \mathrm{~h}$ after CIDR removal on $\mathrm{d}-16$. On $\mathrm{d}-11$ and $\mathrm{d} 0$, blood was collected before $\mathrm{PGF}_{2 \alpha}$ administration. Samples were placed on ice until 


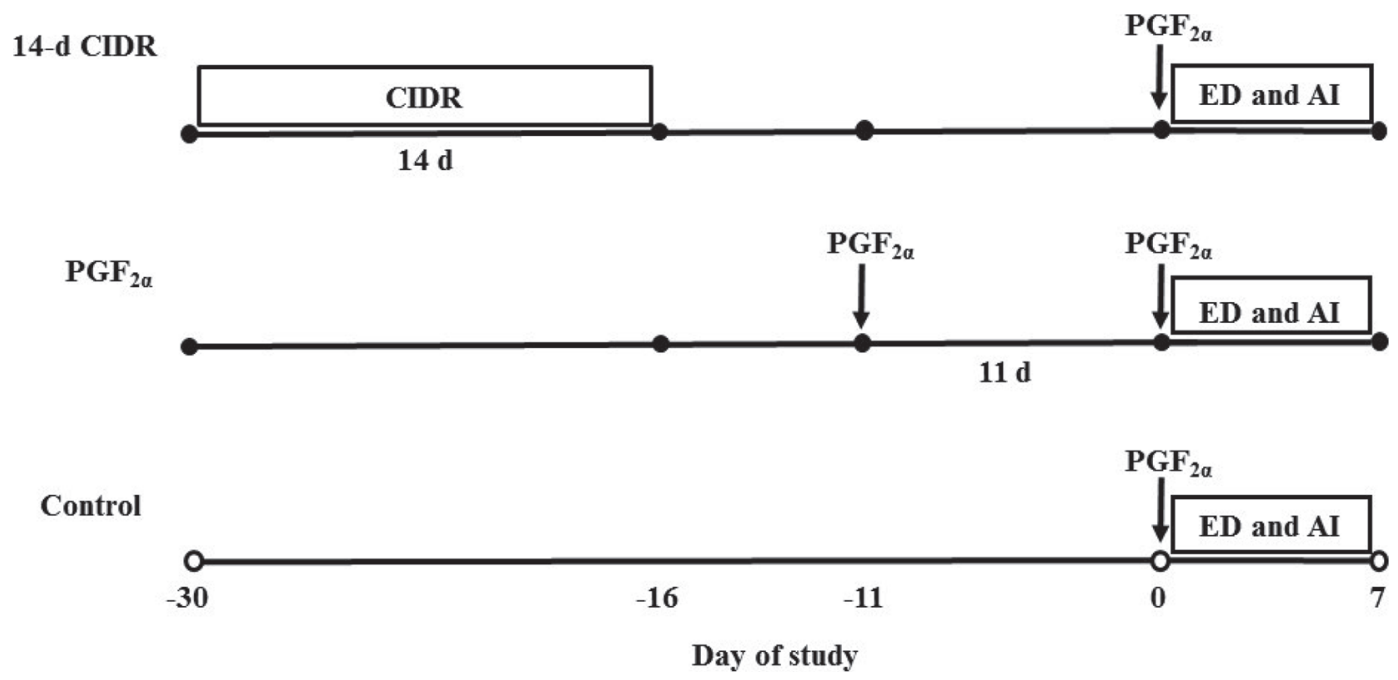

Figure 1. Diagram of activities and treatments. Thirty days $(\mathrm{d}-30)$ before AI eligibility $(\mathrm{d} 0)$, heifers were assigned randomly to 1 of 3 groups: 14-d CIDR presynchronization, $\mathrm{PGF}_{2 \alpha}$ presynchronization, or control (no presynchronization). All heifers received $\mathrm{PGF} 2 \alpha$ on $\mathrm{d}$ 0, followed by estrus detection and AI (ED and AI) for the first $7 \mathrm{~d}$ of breeding eligibility. Closed circles $(\bullet)=$ blood sample; CIDR $=$ controlled internal drug release insert containing $1.38 \mathrm{~g}$ of progesterone; $\mathrm{PGF}_{2 \alpha}=$ injection of $25 \mathrm{mg}$ of dinoprost tromethamine.

centrifuged at $2,500 \times g$ for 10 min. Plasma was stored at $-60^{\circ} \mathrm{C}$ until analysis by RIA (Coat-A-Count Progesterone TKPG1, Siemens Healthcare Diagnostics, Los Angeles, CA). The intra- and interassay CV were 3.3 and $3.5 \%$, respectively.

Generalized linear mixed models (GLMM) were used to assess mean treatment differences. Treatments were considered fixed effects, and sire and heifer were random effects. The responses (1) P/AI during the first $7 \mathrm{~d}$ of breeding eligibility, and (2) proportion of heifers pregnant within $7 \mathrm{~d}$ of breeding eligibility, were assumed binomially distributed with a logit link function (Stroup, 2014). Analysis of treatment differences in heifer BW homogeneity was assessed assuming normally distributed data. Additionally, logistic regression procedures were used to estimate the potential effect of $\mathrm{BW}$ on $\mathrm{P} /$ AI during the first $7 \mathrm{~d}$ based on BW (low $\leq 395.5 \mathrm{~kg}$ or high $>395.5 \mathrm{~kg})$, treatment, and $\mathrm{BW} \times$ treatment interaction. Means were reported as model-based least squares means \pm SEM. Statistical computations were carried out using SAS version 9.4 (SAS/STAT, SAS Institute Inc., Cary, NC).

All heifers in the subset (14-d CIDR, $\mathrm{n}=30 ; \mathrm{PGF}_{2 \alpha}$, $\mathrm{n}=29$ ) exhibited at least one sample with a progesterone concentration $>1.0 \mathrm{ng} / \mathrm{mL}$ before $\mathrm{d}$ 0, providing evidence of cyclicity. Further, progesterone concentrations were $<1.0 \mathrm{ng} / \mathrm{mL}$ for these heifers on the day of detected estrus and AI, providing evidence of detection accuracy and response to $\mathrm{PGF}_{2 \alpha}$ administered on $\mathrm{d} 0$.

Retention of CIDR inserts after $14 \mathrm{~d}$ was $96.7 \%$ $(115 / 119)$. Of the 115 heifers that had a CIDR removed, 4 were not detected in estrus. Therefore, $96.5 \%$
$(111 / 115)$ of heifers were detected in estrus $5 \mathrm{~d}$ after CIDR removal (Figure 2). The 4 heifers with lost CIDR inserts, however, remained in the study and were detected in estrus $2 \mathrm{~d}$ after the CIDR withdrawal date. Therefore, overall, $96.7 \%(111+4=115 / 119)$ of heifers in the 14-d CIDR group were detected in estrus. This result is nearly 22 percentage points higher than in a previous study that reported $75 \%$ of heifers detected in estrus within $5 \mathrm{~d}$ after CIDR removal (Escalante et al., 2013a).

Following $\mathrm{PGF}_{2 \alpha}$ administration on $\mathrm{d} 0$ in the present study, more heifers $(95.8 \% ; 114 / 119)$ in the 14 -d CIDR group were detected in estrus during the first $7 \mathrm{~d}$ than in the $\mathrm{PGF}_{2 \alpha}$ and control groups (74.6 and $66.9 \%$, respectively; $P<0.05$; Table 1 ). Escalante et al. (2013a) reported that $89 \%$ of heifers had a CL $\geq 20 \mathrm{~mm}$ $16 \mathrm{~d}$ after CIDR removal, likely leading to complete luteal regression following $\mathrm{PGF}_{2 \alpha}$ injection and facilitating the detection of estrus. Taken together, results of the present study and those of Escalante et al. (2013a) provide compelling evidence the 14-d CIDR protocol effectively presynchronizes dairy heifers, and administration of $\mathrm{PGF}_{2 \alpha} 16 \mathrm{~d}$ after CIDR removal allows for a high percentage of heifers to be detected in estrus.

Presynchronization with $\mathrm{PGF}_{2 \alpha}$ (11 d before $\mathrm{PGF}_{2 \alpha}$ treatment on $\mathrm{d} 0$ ) resulted in fewer heifers $(74.6 \%)$ detected in estrus during the first $7 \mathrm{~d}$ of eligibility compared with 14-d CIDR heifers $(95.8 \% ; P<0.05$; Table 1). Fogwell et al. (1986) reported similar estrus detection results $(72.7 \%)$ for heifers treated with 2 injections of $\mathrm{PGF}_{2 \alpha} 11 \mathrm{~d}$ apart. Not surprisingly, control heifers in the present study had the lowest percentage (66.9\%) 


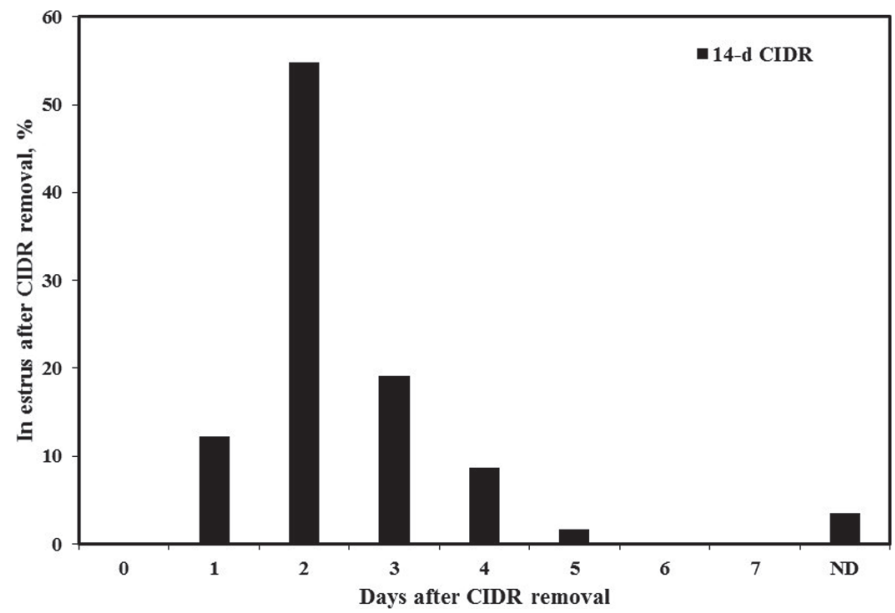

Figure 2. Percentage of heifers in estrus on specific days or that were not detected in estrus (not detected; ND) after removal of a controlled internal drug release insert (CIDR; $1.38 \mathrm{~g}$ of progesterone) in heifers treated with a CIDR for $14 \mathrm{~d}(14-\mathrm{d}$ CIDR $=$ CIDR inserted on $\mathrm{d}-30$ and removed on $\mathrm{d}-16)$.

detected in estrus within $7 \mathrm{~d}$ of breeding eligibility. Given that control heifers were not presynchronized, it is likely these heifers were in various stages of the estrous cycle (relative to follicular growth and CL development) at the time of $\mathrm{PGF}_{2 \alpha}$ treatment on $\mathrm{d} 0$. The percentage of control heifers detected in estrus within $7 \mathrm{~d}$ met expectations for response to a single injection at a random stage of the estrous cycle. However, the response appears to be greater in the present study than described by Escalante et al. (2013a) within $5 \mathrm{~d}$ for heifers in a similar treatment (56.1\%).

Mean days to first AI for heifers detected in estrus in the first $7 \mathrm{~d}$ following $\mathrm{PGF}_{2 \alpha}$ injection was affected by treatment $(P<0.01$; Table 1$)$ and was the fewest for heifers in the 14-d CIDR group $(3.6 \pm 0.4 \mathrm{~d})$, intermediate for heifers in the $\mathrm{PGF}_{2 \alpha}$ group $(5.0 \pm 0.4$ d), and greatest for heifers in the control group (6.8 \pm $0.5 \mathrm{~d}$; Table 1). Pregnancy per AI during the first $7 \mathrm{~d}$ of breeding eligibility was $71.9 \%$ (14-d CIDR), $58.0 \%$
$\left(\mathrm{PGF}_{2 \alpha}\right)$, and $61.7 \%$ (control) and differed between 14-d CIDR and $\mathrm{PGF}_{2 \alpha}$ heifers $(P<0.05$; Table 1$)$. Although there was a small difference in mean BW $(P$ $<0.05$ ) between heifers in 14-d CIDR compared with the $\mathrm{PGF}_{2 \alpha}$ and control groups $(393.2 \mathrm{~kg} \pm 1.5 \mathrm{~kg}, 400.8$ $\mathrm{kg} \pm 1.5 \mathrm{~kg}$, and $398.6 \mathrm{~kg} \pm 1.5 \mathrm{~kg}$, respectively), there was no effect of $\mathrm{BW}$ or $\mathrm{BW} \times$ treatment interaction on $\mathrm{P} / \mathrm{AI}$ within the first $7 \mathrm{~d}$ of eligibility.

Using ultrasonography, Escalante et al. (2013a) reported the 14-d CIDR protocol resulted in $>95 \%$ of heifers having CL $\geq 15 \mathrm{~mm} 16 \mathrm{~d}$ later at the time of $\mathrm{PGF}_{2 \alpha}$ injection. Further, approximately $85 \%$ of heifers had a large follicle (10 to $14.9 \mathrm{~mm}$ ) at the same time (Escalante et al., 2013a). Taken together, this may help explain the excellent fertility reported in the present study for heifers in the 14-d CIDR group. In contrast, follicular development of heifers in the $\mathrm{PGF}_{2 \alpha}$ presynchronization treatment was likely highly variable because these heifers would have been earlier in the estrous cycle at the time of $\mathrm{PGF}_{2 \alpha}$ injection (d 0). Consequently, lack of complete luteolysis following $\mathrm{PGF}_{2 \alpha}$ injection (d 0) may have been a factor for heifers early in the estrous cycle. Increasing the interval between $\mathrm{PGF}_{2 \alpha}$ injections to $14 \mathrm{~d}$ may be beneficial for CL development and responsiveness to the second $\mathrm{PGF}_{2 \alpha}$ injection (d 0); however, the effect on follicle development would likely be determined by whether treated heifers exhibit 2 or 3 follicular waves. Finally, fertility of control heifers, although higher than the average first-service $\mathrm{P} / \mathrm{AI}$ previously reported for US Holstein heifers (Kuhn et al., 2006), was undoubtedly influenced by the various stages of follicular growth and CL development of heifers at the time of $\mathrm{PGF}_{2 \alpha}$ treatment (d 0).

An overall treatment effect was observed for the proportion of heifers pregnant within the first $7 \mathrm{~d}$ of breeding eligibility $(P<0.05)$. A difference $(P<0.05)$ was detected between 14-d CIDR and control groups ( 68.9 vs. $41.3 \%$, respectively), as well as between $14-\mathrm{d}$ CIDR and $\mathrm{PGF}_{2 \alpha}$ groups (68.9 vs. $43.2 \%$, respectively), but not between $\mathrm{PGF}_{2 \alpha}$ and control groups (Table 1).

Table 1. Effect of treatment on fertility responses of dairy heifers

\begin{tabular}{|c|c|c|c|}
\hline \multirow[b]{2}{*}{ Item } & \multicolumn{3}{|c|}{ Treatment $^{1}$} \\
\hline & 14-d CIDR & $\mathrm{PGF}_{2 \alpha}$ & Control \\
\hline $\begin{array}{l}\text { Detected in estrus (first } 7 \mathrm{~d} \text { ), } \% \text { (no./no.) } \\
\text { Pregnancy per AI (first AI), \% (no./no.) } \\
\text { Pregnant (first } 7 \mathrm{~d} \text { ), \% (no./no.) } \\
\text { Days to first AI, }{ }^{2} \text { mean } \pm \text { SEM }\end{array}$ & $\begin{array}{l}95.8^{\mathrm{a}}(114 / 119) \\
71.9^{\mathrm{a}}(82 / 114) \\
68.9^{\mathrm{a}}(82 / 119) \\
3.6 \pm 0.4^{\mathrm{a}}\end{array}$ & $\begin{array}{l}74.6^{\mathrm{b}}(88 / 118) \\
58.0^{\mathrm{b}}(51 / 88) \\
43.2^{\mathrm{b}}(51 / 118) \\
5.0 \pm 0.4^{\mathrm{b}}\end{array}$ & $\begin{array}{l}66.9^{\mathrm{b}}(81 / 121) \\
61.7^{\mathrm{ab}}(50 / 81) \\
41.3^{\mathrm{b}}(50 / 121) \\
6.8 \pm 0.5^{\mathrm{c}}\end{array}$ \\
\hline
\end{tabular}




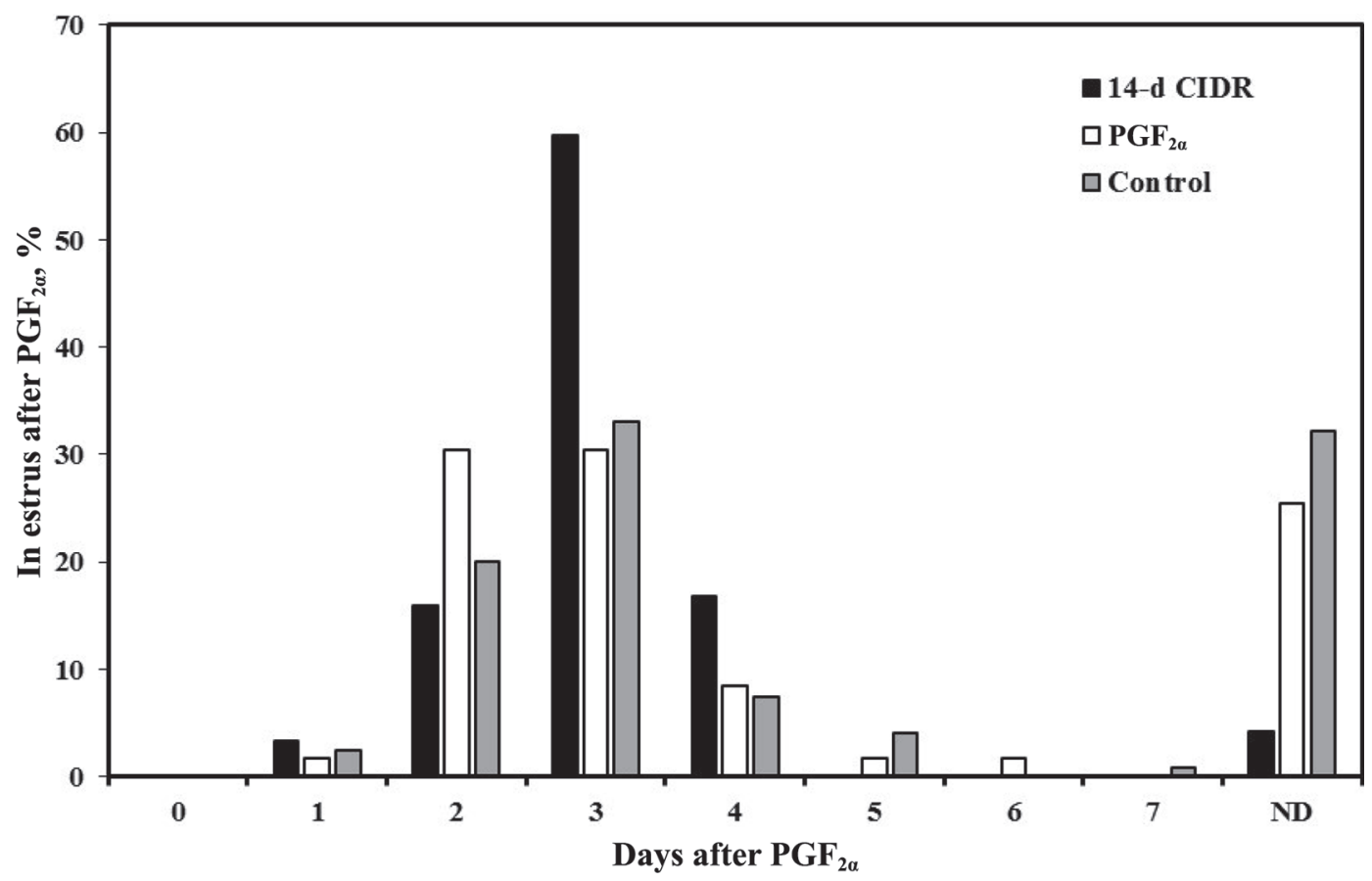

Figure 3. Percentage of heifers in estrus on specific days or that were not detected in estrus (not detected; ND) after PGF ${ }_{2 \alpha}$ injection on $d 0$. $\mathrm{CIDR}=$ controlled internal drug release insert containing $1.38 \mathrm{~g}$ of progesterone; $\mathrm{PGF}_{2 \alpha}=$ injection of 25 mg of dinoprost tromethamine; $14-\mathrm{d}$ $\mathrm{CIDR}=\mathrm{CIDR}$ inserted on $\mathrm{d}-30$ and removed on $\mathrm{d}-16, \mathrm{PGF}_{2 \alpha}$ on $\mathrm{d} 0 ; \mathrm{PGF}_{2 \alpha}=\mathrm{PGF}_{2 \alpha}$ on $\mathrm{d}-11$ and $0 ; \mathrm{Control}^{-} \mathrm{PGF}_{2 \alpha}$ on $\mathrm{d} 0$.

The majority of 14-d CIDR heifers detected in estrus after $\mathrm{PGF}_{2 \alpha}$ injection $(79 \%)$ received $\mathrm{AI}$ on or before $\mathrm{d}$ 3 of eligibility (Figure 3). Coupled with the greatest P/ AI $(71.9 \%)$, presynchronization with a 14 -d CIDR resulted in reduced days to first AI and a greater proportion of heifers pregnant within the first $7 \mathrm{~d}$ compared with heifers presynchronized with $\mathrm{PGF}_{2 \alpha}$ and control heifers. Presynchronization with a single injection of $\mathrm{PGF}_{2 \alpha}$ followed $11 \mathrm{~d}$ later with an injection of $\mathrm{PGF}_{2 \alpha}$ on $\mathrm{d} 0$, however, showed no advantage in proportion of heifers pregnant within the first $7 \mathrm{~d}$ compared with control heifers. A lack of complete luteal regression, based on the day of the estrous cycle when the second injection of $\mathrm{PGF}_{2 \alpha}$ was administered, may explain the heifers in the $\mathrm{PGF}_{2 \alpha}$ presynchronization group that failed to be detected in estrus.

The proportion of heifers pregnant at $120 \mathrm{~d}$ (the length of the breeding period as determined by the feedlot owner) was not different between treatments. Projected days on feed, calculated by adding an estimated gestation length of $280 \mathrm{~d}$ to the interval from breeding program eligibility (d 0) to pregnancy, were $295 \pm 2.6 \mathrm{~d}$ (14-d CIDR), $302 \pm 2.6 \mathrm{~d}\left(\mathrm{PGF}_{2 \alpha}\right)$, and $305 \pm 2.5 \mathrm{~d}$ (control), and differed between the 14-d CIDR and control heifers $(P=0.01)$. Consequently, we developed a partial budget to describe the economic implications of presynchronization with a 14-d CIDR strategy compared with the control for pregnant heif- ers. Because of the 10 fewer projected days on feed, the 14-d CIDR group had a reduced feed cost of $\$ 23.50$ per animal (based on $\$ 2.35$ per heifer per day), coupled with labor savings of $\$ 4.10$ ( $\$ 0.41$ per heifer per day; based on $\$ 15 / \mathrm{h}$, Painter and Gray, 2012). The total reduced cost associated with 14-d CIDR presynchronization was $\$ 27.60$ per heifer. Increased costs associated with presynchronization include materials ( $\$ 10.50$ per CIDR) and additional labor $(\$ 1.25$, based on $\$ 15 / \mathrm{h}$ and $5 \mathrm{~min}$ to complete the treatment task). Consequently, the 14-d CIDR presynchronization treatment cost $\$ 11.75$ per heifer more than the control group. Presynchronization with a 14-d CIDR protocol resulted in an overall treatment balance (total reduced cost - total cost of treatment) of $\$ 15.85$ per heifer, which represents the expected economic benefit to the producer. A limitation of the economic analysis, however, is the exclusion of costs and salvage value associated with open heifers, which was beyond the scope of the study.

With routine growth (height at withers or hip height) and weight monitoring, heifers can be selected for a future breeding eligibility date and managed during the immediate pre-breeding period. Treatment of heifers with a CIDR for $14 \mathrm{~d}$ effectively presynchronized estrus and, when followed by a single $\mathrm{PGF}_{2 \alpha}$ injection $16 \mathrm{~d}$ later, resulted in reduced days to first $\mathrm{AI}$ and an increased proportion of heifers pregnant within the first $7 \mathrm{~d}$ after breeding eligibility compared with heifers pre- 
synchronized with a single $\mathrm{PGF}_{2 \alpha}$ injection $11 \mathrm{~d}$ before breeding eligibility and control (no presynchronization) heifers. Presynchronization of heifers with a 14-d CIDR protocol during the immediate pre-breeding period appears to be promising; however, further research is necessary with a larger group of heifers to more fully describe the potential reproductive and economic benefits.

\section{ACKNOWLEDGMENTS}

The authors thank Darin Mann and employees of M/M Feedlot (Parma, ID) for use of heifers and facilities, and Zoetis (Florham Park, NJ) for providing the CIDR inserts and $\mathrm{PGF}_{2 \alpha}$ for this experiment. The assistance of Brian Voortman, DVM (Herd Health PLLC, Caldwell, ID), is appreciated. This project was supported by the USDA National Institute of Food and Agriculture (Washington, DC; Hatch funds) and the Idaho Agricultural Experiment Station.

\section{REFERENCES}

Ahmad, N., F. N. Schrick, R. L. Butcher, and E. K. Inskeep. 1995. Effect of persistent follicles on early embryonic losses in beef cattle. Biol. Reprod. 52:1129-1135. https://doi.org/10.1095/biolreprod52 .5.1129.

Chebel, R. C., and J. E. P. Santos. 2010. Effect of inseminating cows in estrus following a presynchronization protocol on reproductive and lactation performances. J. Dairy Sci. 93:4632-4643. https:// doi.org/10.3168/jds.2010-3179.

Escalante, R. C., S. E. Poock, and M. C. Lucy. 2013a. Follicular populations and luteal function in dairy heifers treated with a controlled internal drug release insert for 14 days as a method to synchronize the estrous cycle before prostaglandin $\mathrm{F}_{2 \alpha}$ treatment and artificial insemination. J. Dairy Sci. 96:3806-3816. https://doi .org/10.3168/jds.2012-6474.

Escalante, R. C., S. E. Poock, D. J. Mathew, W. R. Martin, E. M. Newsom, S. A. Hamilton, K. G. Pohler, and M. C. Lucy. 2013b. Reproduction in grazing dairy cows treated with 14-day controlled internal drug release for presynchronization before timed artificial insemination compared with artificial insemination after observed estrus. J. Dairy Sci. 96:300-306. https://doi.org/10.3168/jds.2012 -5853 .

Fogwell, R. L., W. A. Reid, C. K. Thompson, M. J. Thome, and D. A. Morrow. 1986. Synchronization of estrus in dairy heifers: A field demonstration. J. Dairy Sci. 69:1665-1672. https://doi.org/ 10.3168/jds.S0022-0302(86)80585-9.

Frazer LLP. 2018. Pages 1-4 in Dairy Farm Operating Trends, June 30, 2018. Frazer LLP, Certified Public Accountants and Consultants, Visalia, CA. Accessed Aug. 15, 2019. https://frazerllp.com/ wp-content/uploads/2019/01/06.30.18-DOT.pdf.

Gabler, M. T., P. R. Tozer, and A. J. Heinrichs. 2000. Development of a cost analysis spreadsheet for calculating the costs to raise a replacement dairy heifer. J. Dairy Sci. 83:1104-1109. https://doi .org/10.3168/jds.S0022-0302(00)74975-7.

Karakaya-Bilen, E., E. S. Ribeiro, R. S. Bisinotto, A. Gumen, and J. E. P. Santos. 2019. Effect of presynchronization with prostaglandin $\mathrm{F}_{2 \alpha}$ before the 5-d timed AI protocol on ovarian responses and pregnancy in dairy heifers. Theriogenology 132:138-143. https:// doi.org/10.1016/j.theriogenology.2019.03.019.

Kuhn, M. T., J. L. Hutchison, and G. R. Wiggans. 2006. Characterization of Holstein heifer fertility in the United States. J. Dairy Sci.
89:4907-4920. https://doi.org/10.3168/jds.S0022-0302(06)72541 $-3$.

Lauderdale, J. W. 2009. ASAS centennial paper: Contributions in the Journal of Animal Science to the development of protocols for breeding management of cattle through synchronization of estrus and ovulation. J. Anim. Sci. 87:801-812. https://doi.org/10.2527/ jas.2008-1407.

Leitman, N. R., D. C. Busch, D. A. Mallory, D. J. Wilson, M. R. Ellersieck, M. F. Smith, and D. J. Patterson. 2009. Comparison of long-term CIDR-based protocols to synchronize estrus in beef heifers. Anim. Reprod. Sci. 114:345-355. https://doi.org/10.1016/ j.anireprosci.2008.10.014.

Lima, F. S., H. Ayres, M. G. Favoreto, R. S. Bisinotto, L. F. Greco, E. S. Ribeiro, P. S. Baruselli, C. A. Risco, W. W. Thatcher, and J. E. P. Santos. 2011. Effects of gonadotropin-releasing hormone at initiation of the 5-d timed artificial insemination (AI) program and timing of induction of ovulation relative to $\mathrm{AI}$ on ovarian dynamics and fertility of dairy heifers. J. Dairy Sci. 94:4997-5004. https:// doi.org/10.3168/jds.2011-4240.

Lima, F. S., E. S. Ribeiro, R. S. Bisinotto, L. F. Greco, N. M. Martinez, M. Amstalden, W. W. Thatcher, and J. E. P. Santos. 2013. Hormonal manipulations in the 5-day timed artificial insemination protocol to optimize estrous cycle synchrony and fertility in dairy heifers. J. Dairy Sci. 96:7054-7065. https://doi.org/10.3168/ jds.2013-7093.

Lormore, M. 2006. The case for a quality dairy replacement program. Pages 155-163 in Proc. Intermountain Nutrition Conference, Salt Lake City, UT. Utah State Univ., Logan, UT.

Mallory, D. A., S. L. Lock, D. C. Woods, S. E. Poock, and D. J. Patterson. 2013. Comparison of sex-sorted and conventional semen within a fixed-time artificial insemination protocol designed for dairy heifers. J. Dairy Sci. 96:854-856. https://doi.org/10.3168/ jds.2012-5850.

Mohd Nor, N., W. Steeneveld, M. C. M. Mourits, and H. Hogeveen. 2012. Estimating the costs of rearing young dairy cattle in the Netherlands using a simulation model that accounts for uncertainty related to diseases. Prev. Vet. Med. 106:214-224.

Moreira, F., C. Orlandi, C. A. Risco, R. Mattos, F. Lopes, and W. W. Thatcher. 2001. Effects of presynchronization and bovine somatotropin on pregnancy rates to a timed artificial insemination protocol in lactating dairy cows. J. Dairy Sci. 84:1646-1659. https: //doi.org/10.3168/jds.S0022-0302(01)74600-0.

NRC. 2001. Nutrient Requirements of Dairy Cattle. 7th rev. ed. Natl. Acad. Sci., Washington, DC.

Painter, K., and C. W. Gray. 2012. Costs and returns for raising Holstein replacement heifers in southwest Idaho, 400-head facility, baby calves to springers (680 days). University of Idaho Extension EBBDR1-12. Accessed Jul. 9, 2019. http://www.uidaho.edu/cals/ idaho-agbiz/livestock-budgets.

Rabaglino, M. B., C. A. Risco, M.-J. Thatcher, I. H. Kim, J. E. P. Santos, and W. W. Thatcher. 2010. Application of one injection of prostaglandin $\mathrm{F}_{2 \alpha}$ in the five-day Co-Synch + CIDR protocol for estrous synchronization and resynchronization of dairy heifers. J. Dairy Sci. 93:1050-1058. https://doi.org/10.3168/jds.2009-2675.

Roche, J. F., E. J. Austin, M. Ryan, M. O'Rourke, M. Mihm, and M. G. Diskin. 1999. Regulation of follicle waves to maximize fertility in cattle. J. Reprod. Fertil. Suppl. 54:61-71.

Silva, T. V., F. S. Lima, W. W. Thatcher, and J. E. P. Santos. 2015. Synchronized ovulation for first insemination improves reproductive performance and reduces cost per pregnancy in dairy heifers. J. Dairy Sci. 98:7810-7822. https://doi.org/10.3168/jds.2015-9704.

Stevenson, J. L., J. A. Rodrigues, F. A. Braga, S. Bitente, J. C. Dalton, J. E. P. Santos, and R. C. Chebel. 2008. Effect of reproductive protocols and reproductive tract score on reproductive performance of dairy heifers and economic outcome of breeding programs. J. Dairy Sci. 91:3424-3438. https://doi.org/10.3168/jds.2007-0804.

Stroup, W. W. 2014. Rethinking the analysis of non-normal data in plant and soil science. Agron. J. 106:1-17. 